\title{
The Effects of Self-help Manual in Addressing Burnout among Nurse Managers
}

\section{Warren Kemuel M Pan}

University of Santo Tomas, Philippines

*Corresponding author: Warren Kemuel M Pan, University of Santo Tomas, Espana Boulevard, Sampaloc, Manila, Philippines, Tel: +63 2 406 1611; E-mail: warrenkemuelpan@yahoo.com

Received date: January 09, 2017; Accepted date: September 29, 2017; Published date: October 09, 2017

Copyright: () 2017 Pan WKM. This is an open-access article distributed under the terms of the Creative Commons Attribution License, which permits unrestricted use, distribution, and reproduction in any medium, provided the original author and source are credited.

\begin{abstract}
High levels of burnout have been documented among nurse managers. This study utilized quasi-experimental design that aims to determine the effectiveness of self-help manual composed of short stories as therapeutic modality for nurse managers experiencing burnout. Thirty-two nurse managers employed in a tertiary hospital in Manila who satisfied the inclusion criteria were assigned to the control and experimental groups. The intervention was given to the experimental group for five days while the control group was asked to continue with their regular routines. Data were collected using Maslach Burnout Inventory - Human Service Survey before and after the intervention which determined the respondents' levels in the three dimensions of burnout. The mean difference for the experimental group yielded a p-value of 0.12 for Emotional Exhaustion, 0.89 for Depersonalization, and 0.06 for the Personal Accomplishment dimension. This study showed that self-help manual is not effective in relieving burnout among nurse managers.
\end{abstract}

Keywords: Self-help manual; Inspirational short stories; Burnout; Nurse managers

\section{Introduction}

Maslach et al. [1] defined burnout as a mental health impairment composed of three dimensions: emotional exhaustion, depersonalization, and a reduced sense of personal accomplishment, which can occur among individuals who work with people in some capacity. Research indicates burnout as frequently seen in careers requiring regular contact with people [2]. As such, high levels of burnout have been documented in the healthcare industry [3]; in particular, the nursing profession [4,5]. Most of the studies, however, have focused on those employed in entry level positions like staff nurses. Yet, burnout has been identified as a major problem for nurse professionals who hold lower management roles like nurse managers [6]. Nurse managers are first-line managers who perform a myriad of administrative duties and ensuring the provision of quality nursing care [7]. These nurse managers are responsible for the day-to-day operations of one nursing unit, evaluating clinical nursing practice; monitoring the delivery of patient care to ensure compliance with regulatory and professional standards; promoting interdisciplinary, collaborative relationships; providing professional development opportunities for personnel; utilizing fiscal and other resources [8].

Burnout greatly affects nurse unit managers in all domains. As such, it has been linked to poor mental and physical health of nurse managers [6], highlighting the importance of preventing this syndrome for staff's well-being. A correlation exists between nurse managers experiencing burnout and their reports of decreased job performance and commitment including low career satisfaction leading to intentions to quit [9].

There is an urgent need to address job burnout for those nurses currently practicing as first line managers [10]. To address this, several approaches and therapeutic modalities have been in existence - some try to treat burnout after it occurred, whereas others focus on how to prevent it. Most discussions of burnout interventions focused primarily on individual-centered solutions such as relaxation techniques, cognitive restructuring, social skills training and attitudinal change which target an employee's coping skills in an effort to make them more resilient to work place stressors [11]. This may be attributed to the fact that organization-directed interventions which take into consideration the impact that work environment has on employees are often complex in the level of collaboration that is necessary and they require a considerable investment of time, effort, and money [1].

In this study, the researcher focuses its attention on the art of selfhelp manual composed of selected inspirational stories as an alternative treatment to burnout. Self-help manuals are defined as an endeavor to help individuals understand themselves and cope with problems by providing literature relevant to their personal situations and specific needs at appropriate times [12]. Self-help materials are reportedly used with a variety of objectives in mind, most frequently to increase awareness, reinforce specific concepts or strategies, and promote lifestyle change [13]; thus, it was seen as an effective treatment with a variety of consumer groups [14]. However, its applicability to the burnout phenomenon lacks empirical evidences.

A researcher made self-help burnout manual in a booklet form was the intervention introduced in this research. This manual was presented in English and compiled five modules. Each module contained one inspirational story adapted from the hit series "Chicken Soup for the Unsinkable Soul". Each story in the self-help manual was carefully chosen to help readers effectively combat burnout. At the end of each module, a guide for reflection was prepared to assist participants in acquiring the moral of the stories and to help them gain insights on successfully combating their present situations. One module was assigned per day for five days, each of which can be completed in approximately $15-20 \mathrm{~min}$ or so. The self-help bibliotherapy manual was subjected to evaluation by a panel of experts 
Page 2 of 5

prior to its utilization in the actual study. A registered psychologist and guidance counselors assessed the completeness, comprehensibility and appropriateness of the contents as well as the framework used in the construction of the manual. Likewise, a pilot study was done to determine the effectiveness of the self-help manual to other groups before its implementation to the study groups.

\section{Module 1 Get Real}

\section{Title: Nursing a legacy}

The objective of this module is to let the participants acknowledge what they presently feel about their work life. This module is composed of story which presents the burnout phenomenon to the reader. It tackles the different signs and symptoms, the risk factors involved as well as the impact of burnout on one's personality and daily living. It aims to confirm the situation that participants are currently experiencing.

\section{Module 2 Get Inspired}

\section{Title: How to be new and different?}

Highlights a story that depicts a movement from isolation to having an inspiration to take action. This module aims to motivate participants towards change using someone else's success stories of overcoming challenges and reaching one's goals.

\section{Module 3 Find Your Support}

\section{Title: Tzippie}

Discusses the importance of support networks. It intends to convince participants to engage in fruitful social relationships most especially in times of difficulties.

\section{Module 4 Take Control}

\section{Title: Choose how to start your day}

Includes a story that illustrates reassessment of oneself. It aims to engage participants to reevaluate their goals, priorities and dreams to take positive steps towards a better existence.

\section{Module 5 Make a Plan}

\section{Title: The day at the beach}

Depicts a story which discusses the importance of outlining a plan of action on how to move from being dominated by feelings of frustration to a place of action. It encourages participants to always prepare in everything that they are in and to develop positive perspective in life.

\section{Methods}

This study utilized a Quasi-Experimental Pre-test and Post-test Control Group design. Utilizing this research design, the researcher was able to determine the significant difference in the participants' three dimension of burnout in terms of their pre-test and post-test scores as measured by the Maslach's Burnout Inventory (Table 1).

\begin{tabular}{|c|c|c|c|c|c|c|}
\hline $\begin{array}{l}\text { Demographic } \\
\text { Variable }\end{array}$ & Experimental & & Control & & Total & \\
\hline & Group & & Group & & & \\
\hline & $\mathrm{N}=16$ & & $\mathrm{~N}=16$ & & $\mathrm{~N}=32$ & \\
\hline Gender & $\mathbf{F}$ & $\%$ & $\mathbf{F}$ & $\%$ & $\mathbf{F}$ & $\%$ \\
\hline Male & 2 & $13 \%$ & 2 & $13 \%$ & 4 & $13 \%$ \\
\hline Female & 14 & $87 \%$ & 14 & $87 \%$ & 28 & $87 \%$ \\
\hline \multicolumn{7}{|l|}{ Age } \\
\hline $20-30$ & 1 & $6 \%$ & 1 & 65 & 2 & $6 \%$ \\
\hline $31-40$ & 8 & $50 \%$ & 7 & $44 \%$ & 17 & $53 \%$ \\
\hline $41-50$ & 3 & $19 \%$ & 3 & $19 \%$ & 6 & $19 \%$ \\
\hline $51-60$ & 3 & $19 \%$ & 4 & $25 \%$ & 7 & $22 \%$ \\
\hline \multicolumn{7}{|l|}{ Marital Status } \\
\hline Single & 3 & $19 \%$ & 3 & $19 \%$ & 6 & $19 \%$ \\
\hline Married & 12 & $75 \%$ & 12 & $75 \%$ & 24 & $75 \%$ \\
\hline Separated & 1 & $3 \%$ & 0 & $0 \%$ & 1 & $3 \%$ \\
\hline Widowed & 0 & $0 \%$ & 1 & $3 \%$ & 1 & $3 \%$ \\
\hline \multicolumn{7}{|l|}{$\begin{array}{l}\text { Educational } \\
\text { Attainment }\end{array}$} \\
\hline $\begin{array}{l}\text { Bachelor's } \\
\text { Degree }\end{array}$ & 12 & $75 \%$ & 12 & $75 \%$ & 24 & $75 \%$ \\
\hline Master's Degree & 4 & $25 \%$ & 4 & $25 \%$ & 8 & $25 \%$ \\
\hline $\begin{array}{l}\text { Doctorate } \\
\text { Degree }\end{array}$ & 0 & $0 \%$ & 0 & $0 \%$ & 0 & $0 \%$ \\
\hline \multicolumn{7}{|l|}{$\begin{array}{l}\text { Years Of Work } \\
\text { Experience }\end{array}$} \\
\hline $1-5$ & 1 & $6 \%$ & 1 & $6 \%$ & 2 & $6 \%$ \\
\hline $6-10$ & 7 & $48 \%$ & 8 & $50 \%$ & 15 & $47 \%$ \\
\hline $11-15$ & 4 & $25 \%$ & 3 & $19 \%$ & 7 & $22 \%$ \\
\hline $16-20$ & 0 & $0 \%$ & 0 & $0 \%$ & 0 & $0 \%$ \\
\hline $21-25$ & 1 & $6 \%$ & 1 & $6 \%$ & 2 & $6 \%$ \\
\hline$>26$ & 3 & $19 \%$ & 3 & $19 \%$ & 6 & $10 \%$ \\
\hline
\end{tabular}

Table 1. Characteristics of the study sample.

The Maslach Burnout Inventory - Human Services Survey (MBIHSS) was designed to gauge burnout of people working in the health care occupations such as nursing. The MBI-HSS consists of 22 item self-report questionnaire that take approximately $10-15 \mathrm{~min}$ to complete. The questionnaire measures the three subscales of burnout namely: emotional exhaustion (items: $1,2,3,8,13,14,16,20$ ), depersonalization (items: 4, 7, 9, 12, 17, 18, 19) and personal accomplishment (items: 5, 6, 10,11, 22). Each item has a 7-point rating scale indicating the frequency of experiencing each symptom $(0=$ never, $6=$ everyday). Cutoffs have been determined to separate high, moderate 
and low risk levels for each of the three types of burnout based on a normative data set for healthcare professionals.

\section{Data gathering procedure}

Prior to the gathering of data, authorization to conduct this research was sought from the Medical Center's chief nurse and medical director. The nature of the research and the intervention protocol were discussed and carefully analyzed by the Institutional Review Board. Permission to acquire a master list of all nurse unit managers of the institution was also coordinated. It was also coordinated with the chief nurse to schedule all nurse managers who will be part of the experimental group in the morning shift so as to avoid any distractions from their work. Further, a request to meet all nurse unit managers in one venue for the pre-test and for the implementation of the study intervention for five consecutive days was, likewise, done.

Once all nurse unit managers were in the designated venue, they were invited to participate in the current study through an informed consent which was provided by the researcher. Participants were instructed to read an information sheet and sign a consent form, confirming that they understood the aims and objectives of the research. After their approval, they were asked to answer the MBI HSS to assess whether or not they are burnout. The same instructions were given to all the respondents. Emphasis that there were no time limit and no right or wrong answers were observed. The respondents were encouraged to answer all items as sincerely as possible. More so, they were informed that the results will be held strictly confidential. The questionnaire being a burnout measure was not mentioned.

Consequently, answers collected were analyzed and interpreted against the norms for human services medicine subgroup which tells the burnout levels of the respondents for each component. The process of scoring analysis was supervised by a registered psychologist. To attain homogeneity, only those nurse unit managers with moderate to high degree in any of the three dimensions of burnout was chosen to undergo the research intervention. They were randomly distributed to either the experimental or the control group utilizing the fishbowl technique to eliminate selection bias. Respondents were divided equally to the two groups.

The subjects who were placed in the experimental group underwent the study intervention. The control group, on the other hand, was not given any treatment but was asked to go on with their daily routines and their normal way of coping with stress. All participants in both groups, however, were not informed that they were assigned to either the experimental or the control groups.

When everyone and everything was settled, the sessions were conducted every other day for five (5) days with one session lasting for 30 min each. The sessions were held in one of the rooms in the nursing service office. The room is well lit and is free from outside noise. The sessions were conducted every 3 O'clock in the afternoon after the morning shift to avoid distracting nurse managers in their performance of their nursing duties and responsibilities.

During the sessions per se, all participants were given a copy of the self-help burnout manual composed of selected inspirational stories. Participants were instructed to read the assigned module for the day for 10-15 $\mathrm{min}$ or so. After which, they were given another $15 \mathrm{~min}$ to reflect on the short stories that they have just read using the guide for reflection provided at the end of the module. Instructions were given to the experimental group to refrain from discussing the intervention to their fellow nurse managers and not to read any materials of the same value. After each session, the self-help manuals were retrieved from the participants. The sessions were conducted in the presence of a guidance counselor to address any harm that might happen during the sessions.

In order to determine if self-help manual composed of selected inspirational stories yielded positive effect on the different dimensions of burnout among nurse managers, a post-test using the same assessment tool in the pre-test was administered simultaneously to both groups in the same venue. The post-test was given after the fifth bibliotherapeutic session was completed by the experimental group. Again, the respondents were encouraged to answer all of the items as sincerely as possible and that confidentiality concerning the test results was assured. Exactly, after the conduct of the post-test, de-briefing was done to the participants of the study, both to the experimental and control groups.

\section{Results and Discussion}

\section{General characteristics of the participants}

1. What are the mean scores and standard deviation values of the different dimensions of burnout among nurse unit managers assigned in the experimental and control group as measured by the Maslach burnout inventory prior to the intervention? (Table 2).

\begin{tabular}{|l|l|l|}
\hline Dimensions & Experimental & Control \\
\hline & Mean (SD) & Mean (SD) \\
\hline Emotional Exhaustion & $39.50(5.84)$ & $36.31(4.60)$ \\
\hline & (High) & (High) \\
\hline Depersonalization & $6.69(6.33)$ & $8.94(6.82)$ \\
\hline & (Moderate) & (Moderate) \\
\hline Personal Accomplishemnts & $22.13(9.05)$ & $24.06(9.007)$ \\
\hline & (High) & (High) \\
\hline
\end{tabular}

Table 2: Pre-test mean scores and standard deviation values of the experimental and control groups as measured by the Maslach Burnout Inventory.

The experimental group yielded a pre-test mean scores of $\mathrm{EE}=39.5$, $\mathrm{DP}=6.69$ and $\mathrm{PA}=22.13$, respectively while the control group as presented in the table below scored 36.31 for EE, 8.94 for DP and 24.06 for PA. Comparing the group's aggregated scores to the MBI mean norm, both groups resulted to similar burnout categorization, high for $\mathrm{EE}$ and PA and moderate for the DP subscale. It is interesting to note that the experimental group had a higher EE mean and lower DP and PA scores as contrasted against the control group.

The results affirm several studies stating that the nursing profession has been identified to be at a great risk for burnout $[15,16]$. Demerouti has identified that a great cause of stress and emotional taxing is experienced when caring for people and dealing with patient's concerns and feelings [17]. Burnout is obviously a well identified problem for nurse managers considering all of the research that is available. However, there are conflicting findings on the overall satisfaction of nurses. Patrick and Lavery found about $89 \%$ of nurses were happy with nursing as their career choice. Buerhaus found similar results with $87 \%$ of nurses were satisfied being a nurse [18]. On the 
Page 4 of 5

other hand, only one-half of nurses in North Carolina are happy with their jobs, and $20 \%$ are definitely unhappy [19]. Flinkman found that one-quarter of nurses frequently think of quitting nursing and only one-quarter never think of giving up their nursing career [20].

\begin{tabular}{|l|l|l|}
\hline Dimensions & Experimental & Control \\
\hline & Mean (SD) & Mean (SD) \\
\hline Emotional Exhaustion & $35.13(9.09)$ & $36.81(6.45)$ \\
\hline & $($ High) & (High) \\
\hline Depersonalization & $6.44(7.06)$ & $7.375(7.08)$ \\
\hline & $($ Moderate) & (Moderate) \\
\hline Personal Accomplishment & $17.19(9.98)$ & $22.57(10.41)$ \\
\hline & $($ High $)$ & $($ High $)$ \\
\hline
\end{tabular}

Table 3: Post-test mean scores and standard deviation values of the experimental and control groups as measured by Maslach Burnout Inventory.
2. What are the mean scores and standard deviation values of the different dimensions of burnout among nurse unit managers assigned in the experimental and the control group as measured by the Maslach Burnout Inventory after the intervention? (Table 3).

The experimental group showed a post-test mean scores of 35.13, 6.44 and 17.19 for the EE, DP and PA subscales, respectively. The control group on the other hand resulted to a mean score of 36.81 for EE, 7.38 for DP and 22.57 for PA subscale. Similar patterns that of the pre-test were noted from the post test results when compared to the MBI mean norms. The post-test mean score still falls in the High category for the EE and PA component while "moderate" for the DP.

There is, however, an observed reduction in the post-test mean scores of both groups. The experimental group yielded a reduction of 4.37 for EE, 0.25 for DP and 4.94 for PA dimensions. The control group, on the other hand, yielded a decrement of 0.50 for EE, 1.56 for DP and 1.5 for PA component.

3. Is there a significant difference in the post-test mean of the different dimensions of burnout between nurse managers assigned in the experimental and control groups? (Table 4)

\begin{tabular}{|l|l|l|l|l|}
\hline Variables & Experimental & Control & T-value & Pecision \\
\hline & Mean & Mean & & \\
\hline Emotional Exhaustion & 35.13 & 36.81 & 0.05 & 0.96 \\
\hline Depersonalization & 6.44 & 7.38 & 0.38 & 0.71 \\
\hline Personal Accoplishment & 17.19 & 22.57 & 1.49 & Accept \\
\hline
\end{tabular}

Table 4: Difference in the post-test mean scores of the experimental and control groups as measured by Maslach Burnout Inventory.

An independent t-test was utilized on the mean scores of both the experimental and control groups to determine if there was a significant difference in the change scores after the administration of the study intervention. Based on the table above, it was found out that that there were no statistically significant differences between the experimental and control groups post-test mean score for the emotional exhaustion (p-value=0.96), depersonalization $\quad(p$-value $=0.71)$ or personal accomplishments $(\mathrm{p}$-value $=0.49)$ since all the $\mathrm{p}$-value results surpassed the 0.05 level of significance. Thus, we accept the null hypothesis.

The results showed that there is no significant difference in the e post-test mean scores of the experimental and control groups which negates studies indicating that interventions like self-help manual are beneficial among nurse managers and that people who take part in burnout intervention programs generally experience less burnout than their counterparts who do not.

4. Is there a significant difference between the pre-test and post-test mean scores when grouped according to (Table 5):

\section{- Experimental Group}

\section{- Control Group}

The researcher utilized the paired t-test on this table since participants were measured before and after the administration of the self-help manial sessions. For the emotional exhaustion, the experimental and control groups yielded a p-value of 0.30 and 0.84 respectively. Meanwhile, the depersonalization subscale resulted to a pvalue of 0.89 for the experimental and 0.48 for the control group.
Lastly, for the personal accomplishment dimension, the experimental group yielded a $\mathrm{p}$-value of 0.06 while the control group posted a $\mathrm{p}$ value of 0.68 . Scores for both groups, however, exceeded the 0.05 level of significance, which tells us that there were no significant difference between the pre-test and post-test scores. Thus, we accept the null hypothesis.

Though statistically insignificant, means scores for the three dimensions of burnout posted an observed decrease specially for the experimental group. The treatment group yielded a reduction in the emotional exhaustion (4.37) and depersonalization (0.25) components while an increase of 4.94 for the personal accomplishment scale.

Although the intervention was not given to the control group, the mean scores of these nurse managers in the depersonalization and personal accomplishment subscales lowered (from 8.94 pre-test to 7.38 post-test) and (from 24.06 pre-test to 22.56 post-test) respectively. This decrement indicates a change for both dimensions to a certain extent. However, this reduction in scores is smaller as compared to the decrement in the mean scores of nurse managers assigned in the experimental group ( $\mathrm{EE}=39.50$ to $35.13, \mathrm{DP}=6.69$ to 6.44 and $\mathrm{PA}=22.13$ to 17.19 ) which implies the effectiveness of the self-help manuals at a certain extent, however, does not reach the statistical significance level.

Self-help manual, the intervention in this experimental study involves reading selected short inspirational stories as a means of treatment for burnout. This mental activity can lead to cognitive restructuring wherein negative thoughts are altered and transformed 
into something positive. Since nurse managers in this research study involving the use of bibliotherapy were individuals who manifested emotional exhaustion, cynism and reduced sense of personal accomplishments, their mental efforts centered on negative and selfdefeating thoughts. Thus, the researcher's contention is to redirect these negative thoughts to something affirmative through the use of self-help manual involving selected inspirational short stories.

\begin{tabular}{|l|l|l|l|l|l|}
\hline Subscales & Pre-test & Post-test & T-value & P-value & Decision \\
\hline & Mean & Mean & & & \\
\hline $\begin{array}{l}\text { Emotional } \\
\text { Exhaustion }\end{array}$ & & & & & \\
\hline Experimental & 39.5 & 35.13 & 1.62 & 0.12 & Accept \\
\hline Control & 36.31 & 36.81 & 0.21 & 0.85 & Accept \\
\hline Depersonalization & & & & & \\
\hline Experimental & 6.69 & 6.44 & 0.14 & 0.89 & Accept \\
\hline Control & 8.94 & 7.38 & 0.718 & 0.484 & Accept \\
\hline $\begin{array}{l}\text { Personal } \\
\text { Accomplishments }\end{array}$ & & & & & \\
\hline Experimental & 22.13 & 17.19 & 1.97 & 0.06 & Accept \\
\hline Control & 24.06 & 22.56 & 0.419 & 0.681 & Accept \\
\hline
\end{tabular}

Table 5: Difference in the pre-test and post-test mean scores of theexperimental and control groups as measured by Maslach Burnout Inventory.

The foregoing results negates the previous research studies, on the effects of self-help manual on several mental health impairments like depression, pessimism, panic disorders among others. Having a noticeable reduction in the EE and DP scores, it is indicative of the appropriateness of the intervention for addressing this phenomenon. However, given the high levels in the emotional exhaustion and depersonalization components, it is likely that the number of sessions may have been inadequate to create an effect that would be statistically discernable. Studies involving the use of self-help manual as an intervention, however, lack clear design for implementation (Riordan, 1996) which includes the duration of each session and for how long the therapy should be done. Several studies conducted self-help manual session for three weeks to a maximum of eight months and produced the desired effects.

\section{Conclusion}

Consistent with the outcomes of this research, the following conclusions are established. Burnout phenomenon is really a major concern for nurses in lower management positions. Further, nurse managers show to have high levels in the emotional exhaustion component of burnout. Yet, nurse managers are still able to present high sense of personal accomplishments towards work though burnout in the emotional exhaustion dimension. Lastly, Self-help bibliotherapy composed of selected inspirational short stories is not effective in bringing about change in the respondents' different dimensions of burnout.

\section{References}

1. Maslach C, Schaufeli W, Leiter M (2001) Job burnout. Annu Rev Psychol 52: $397-422$.

2. Schaufeli WB, Van Dierendonck D (1993) The construct validity of two burnout measures. J Organ Behav 14: 631-647.

3. Leiter MP, Maslach C (2004) Areas of worklife: A structured approach to organizational predictors of burnout. Research in Occupational Stress and Well-Being 3: 91-134.

4. Bourbonnais R, Comeau M, Vezina M (1999) Job strain and evolution of mental health among nurses. J Occup Health Psychol 4: 95-107.

5. Schaefer J, Moos R (1996) Relationship, task and system stressors in the health care workplace. J Community Appl Soc Psychol 3: 285-298.

6. Laschinger H (2004) Hospital nurses perceptions of respect and organizational justice. J Nurs Adm 34: 354-364.

7. Courtney J, Yacopetti C, James A, Walsh K, Finlayson K (2002) Comparison of roles and professional development needs of nurse executives working in metropolitan, provincial, rural or remote settings in Queensland. Aust J Rural Health 10: 202-208.

8. Sullivan E, Decker P (2005) Effective leadership and management in nursing, Prentice Hall, Upper Saddle River.

9. Aiken L, Clarke S, Sloane D, Sochaliski J, Silber J (2002) Hospital staffing, organization and quality of care: Cross-national findings. Int J Qual Healthc 14: 5-13.

10. Gray-Toft P, Anderson J (1985) Organizational stress in the hospital: Development of a model for diagnosis and prediction. Health Serv Res 19: 753-774.

11. Hatinen MK (2007) Comparing two burnout interventions: Perceived job control mediates decreases in burnout. Int J Stress Manag 14: 227-248.

12. Hebert TP, Kent R (2002) Nurturing social and emotional development in gifted teenagers through young adult literature. Roeper Rev 22: 167-171.

13. Campbell LF, Smith TP (2003) Integrating self-help books into psychotherapy. J Clin Psychol 59: 177-186.

14. Cuijpers P, Van Straten A, Smit F (2005) Psychological treatment of latelife depression: A meta analysis of randomized controlled trials. Int J Geriatr Psychiatry 21: 1139-1149.

15. Altun I (2002) Burnout and nurses' personal and professional values. Nurs Ethics 9: 969-278.

16. Bakker A, Demerouti E, Schaufeli W (2002) The validity of the Maslach Burnout Inventory - General survey: An internet study. Anxiety Stress Coping 15: 245-260.

17. Demerouti EB (2000) A model of burnout and life satisfaction amongst nurses. J Adv Nurs 32: 454-464.

18. Buerhaus PA (2007) Recent trends in the registered nurse labor market in the U.S: Short-run swings on top of long-term. Nurs Econ 25: 59-66.

19. Lacey L, Shaver (2002) Nursing workforce planning regions. North Carolina trends in nursing: 1982-2000, NC: The North Carolina Center for Nursing.

20. Flinkman ML (2008) Explaining young registered Finnish nurses' intention to leave the profession: A questionnaire survey. Int J Nurs Stud 45: 727-739. 